\title{
Práticas teatrais e práticas escolares de leitura
}

\author{
Mei Hua Soares \\ Doutoranda em Educação/ USP \\ Área de Concentração: Linguagem e Educação \\ Orientadora: Neide Luzia de Rezende
}

Resumo: Este projeto tem por objetivo investigar práticas de leitura realizadas por alguns grupos de teatro, contemplados pela Lei de Fomento ao Teatro (SP), que apresentam como cerne, ou como interesse subjacente à pesquisa desenvolvida, o trabalho junto a jovens. Considerando que as ações nesses grupos apresentam ênfase no processo que, por sua vez, envolve leituras e investigação de temas caros aos artistas durante suas criações, visa-se refletir sobre a existência de um possível conceito ou ideia de formação. A partir da observação dos processos de pesquisa e seus desdobramentos cênicos, da coleta de informações acerca das leituras realizadas coletivamente, pretendese verificar em que medida há uma dimensão pedagógica efetiva que se funda nesses trabalhos compartilhados entre artistas e jovens e como ela se dá.

Palavras-chave: formação, jovem, processo

Title: Theatrical practices and school reading practices

Abstract: This project aims to investigate practices of reading performed by some theater groups, contemplated by the Law of the Theatre Development (SP), which have as the heart or as an interest underlying the developed research, a work with young people. Whereas the actions on those groups present emphasis on process which, in turn, involves reading and researching of important issues to the artists in their creations, it is aimed to reflect upon the possible existence of a concept or idea of training. From the observation of the research processes and its scenic unfolding, the collection of information about the readings performed collectively, we intend to explore whether there is a effective teaching dimension which is based on these shared works between artists and young people and how it happens.

Keywords: formation, young, process

Título: Prácticas teatrales y las prácticas escolares de lectura

Resumen: Este proyecto tiene como objetivo investigar prácticas de lectura realizadas por algunos grupos de teatro, contemplados por la Ley de Fomento al Teatro (SP), que tienen como base o como interés subyacente a la investigación desarrollada, el trabajo con jóvenes. Considerando que las acciones de estos grupos ponen énfasis en el proceso, que a su vez, implica lecturas e investigación de temas que conciernen a los artistas durante sus creaciones, se intentará reflexionar sobre la posible existencia de un concepto o idea de formación. A partir de la observación de los procesos de investigación y sus desdoblamientos escénicos, de la recopilación de información acerca de las lecturas colectivas, tenemos la intención de verificar en qué medida existe una dimensión pedagógica efectiva que se basa en esos trabajos compartidos entre artistas y jóvenes, y cómo esta dimensión sucede.

Palabras-clave: formación, joven, proceso 
Este projeto tem por objetivo investigar a leitura de jovens que participam de projetos relacionados a grupos de teatro, contemplados pela Lei Municipal de Fomento ao Teatro para a Cidade de São Paulo e que apresentam como contrapartida social, ou como cerne de pesquisa, o trabalho junto a jovens e adolescentes. Considerando que em tais grupos a ênfase está no processo de pesquisa, o qual envolve leituras e investigação de temas e assuntos por parte dos artistas, visa-se cotejar a leitura realizada nessas práticas sociais com as de âmbito escolar. A hipótese primeira seria a de que o jovem, enquanto aluno de ensino básico, estaria menos propenso a se envolver com a leitura no ambiente escolar por motivos diversos, tais como inadequação dos textos aos seus interesses leitores, despreparo dos mediadores (docentes), rebeldia contra uma cultura institucionalizada, ausência de identificação com os elementos literários (linguagem, personagens, temas) e extraliterários (autor, posicionamento crítico), sentimento de inutilidade da leitura e da literatura entre outros fatores, ao passo que, ao adquirir um caráter condicional para se alcançar uma formação cultural por ele escolhida e almejada - a formação cênica proporcionada por grupos teatrais a jovens de camadas socioeconômicas menos favorecidas -, a leitura passaria a representar importante dispositivo de inserção sociocultural adquirindo outro valor simbólico.

Lecionando na rede estadual de ensino básico de São Paulo desde 2004, a leitura entre os alunos sempre consistiu em ponto de partida para minhas atividades em sala de aula. $\mathrm{O}$ contato constante com as dificuldades de leitura dos alunos (e também dos professores) de escola pública despertou meu interesse sobre o assunto e a necessidade de pesquisar os diferentes aspectos envolvidos no processo de leitura. Em 2006, iniciei a pesquisa de mestrado relacionada ao ensino de leitura e literatura para jovens alunos envolvendo a vertente literária marginal-periférica. Participando das reuniões do grupo de estudos de pós-graduação da área de Linguagem e Educação (FEUSP), pude entrar em contato com textos que propiciaram discussões sobre questões relacionadas às práticas de leitura e ao ato leitor, entre eles, textos da estética da recepção.

Concomitantemente ao trabalho no magistério e à pesquisa acadêmica, acompanhei o processo de criação dramática de alguns grupos de teatro (em especial, o da Cia. Antropofágica, Projeto PY, e Paidéia) que promovem a interação de jovens (e de não artistas) e o núcleo profissional em suas pesquisas e peças, e pude perceber que as leituras realizadas pelos integrantes (inseridos em grupos politizados) resultavam para 
eles em um valor simbólico bastante distinto daquele que a leitura escolar geralmente apresenta para alunos de semelhantes condições e faixas etárias.

Esses grupos foram contemplados pelo Programa de Fomento ao Teatro para a Cidade de São Paulo (Lei 13.279) que, desde 2002, seleciona grupos de teatro de acordo com seus projetos de pesquisa e a eles destina verbas para a realização de seus projetos cênicos. Um dos requisitos para a aprovação de tais projetos é o da contrapartida social que, por vezes, faz com que alguns grupos se reportem pontualmente às populações de baixa renda (mediante apresentações gratuitas ou a preços populares em escolas, sindicatos, comunidades periféricas; debates, palestras e oficinas para as camadas economicamente desprivilegiadas etc.) como forma de garantir que o projeto teatral obedeça às orientações do programa. Há, entretanto, grupos que, independentemente de receberem essa verba pública ou não, mantêm seus estudos e sua pesquisa voltados aos meios sociais excluídos da cultura autorizada, como cerne e norte de seu teatro e de suas preocupações estéticas e políticas.

O trabalho com a leitura está presente nas práticas teatrais desses grupos não só quando se debruçam sobre textos dramáticos ou obras literárias que servirão de base para a encenação, mas também a textos vários que de uma forma ou de outra farão parte do tema central de suas pesquisas ou que travarão diálogos nas suas adjacências. Alguns desses grupos reforçam a ideia da leitura por parte dos atores e membros como maneira de inserção sociopolítica, seja na sociedade ou no circuito teatral e realizam suas atividades por intermédio de processos criativos colaborativos ou coletivos.

Embora ciente de que se trata de práticas de leitura distintas - as do teatro e as da escola -, com funções e objetivos específicos, é de se perguntar que aspectos envolvidos em ambos os processos poderiam confluir e motivar a leitura dos jovens (tanto alunos como iniciantes na arte dramática), uma vez que partimos do pressuposto teórico de que, no mundo contemporâneo, as práticas escolares devem ecoar as práticas sociais. O que muda nesta relação entre texto-leitor (jovem) nas leituras escolares e nas demais práticas de leitura realizadas fora das instituições de ensino? Qual o valor que as leituras extraescolares apresentariam para o jovem aluno e para os mediadores da leitura (professores e coordenadores dos projetos de leitura e dramaturgia)? Existiria uma concepção de formação advinda desses grupos que foram fomentados ao longo de algumas edições do programa de fomento ao teatro? 
Revista "AspaS" - № 1 - 2011 - Anais do Primeiro Seminário de Pesquisas em Andamento uspac do Programa de Pós-Graduação em Artes Cênicas da Universidade de São Paulo.

O presente projeto de pesquisa pretende abordar, portanto, não só o universo de leitura - de obras literárias, entre as quais se encontram textos dramáticos e dramatúrgicos, de textos teóricos, de cenas - do jovem que está inserido em coletivos teatrais, mas também investigar se existe uma ideia de formação que se origina a partir das ações dos grupos de teatro que se reportam aos jovens em uma possível perspectiva pedagógica e política que complemente e sustente a dimensão estética.

As modificações paradigmáticas ocorridas na passagem entre aquilo que se denomina "modernidade" e o que se conceituou como "pós-modernidade", ou “contemporâneo" (FAVARETTO, 2005), traçaram linhas de confronto entre o caráter "inventivo" ou "criativo" da arte, ou seja, a arte concebida enquanto instrumento que "desperta a sensibilidade e matiza os efeitos de uma formação (Bildung) essencialmente racional e instrumental" (FAVARETTO, 2010) e entre a perspectiva contemporânea de arte situada numa zona de risco, cujo estranhamento e questionamento seriam constantes quanto ao lugar da própria arte ou de sua função. Considerando esse panorama, em que medida a arte poderia contribuir para se pensar uma outra formação escolar, menos atrelada à reprodução e reafirmação de valores e regras que já não condizem com o contexto contemporâneo ou com ele pouco dialogam? A convivência entre o permanente e o fluxo na educação escolar poderia se dar de quais maneiras, de modo que um não se sobrepusesse ao outro? Em que medida as práticas de alguns coletivos de teatro poderia contribuir para se pensar nestas questões?

Na medida em que a arte contemporânea apresenta-se difusa e um tanto quanto indefinida, pois a desconstrução, o deslocamento e a investigação mostram-se traços intrínsecos a ela, o ponto de apoio está essencialmente no processo que é realizado pelos artistas, no percurso trilhado em meios às variantes que dialogam com o ato de criação. Essa ênfase processual poderia fornecer subsídios para se pensar uma formação cujo enfoque não seja mais teleológico, mas sim centrado nas experimentações e em seus possíveis, mas não prescritivos, desdobramentos. A finalidade educacional, cuja argumentação poderia ser colocada em xeque, uma vez que não atende aos ideais de democratização e de "construção da cidadania", nem aos fins propedêuticos, ou ainda não supre as demandas do mercado profissional, poderia ser repensada sob esse viés processual no qual se encontra mergulhada a arte contemporânea.

Os grupos de teatro que desenvolvem processos criativos colaborativos defendem um fazer artístico que não se resume a um produto final, já que a tônica está 
no processo, e defendem a sustentação de uma organização grupal que rompa com a relação diretor-ator em conotação de comando-obediência. Nos processos colaborativos a organização está pautada pelas decisões coletivas ou consensuais; pelas "hierarquias móveis" "1 que preservam ou acumulam funções que, no entanto, podem ser discutidas por pessoas diferentes e em momentos distintos, e pelos longos, por vezes exaustivos, processos de pesquisa e criação.

Tais fatores também serão abordados, já que fundamentam o modus operandi da estrutura dos grupos e terminam por delinear diferentes equações hierárquicas, as quais implicam direta e indiretamente na prática criativa, que poderiam ser cotejadas com as relações que se estabelecem na escola.

No âmbito da leitura na escola, as orientações curriculares, presentes nos Parâmetros Curriculares Nacionais para o Ensino Fundamental (PCN) e nas Orientações Curriculares Nacionais do Ensino Médio (OCNEM), apontam para mudanças no tratamento dado ao trabalho com leitura em sala de aula. Na grade curricular do curso de Ensino Fundamental II da rede estadual paulista constam aulas específicas de Leitura (incluídas na grade pela disciplina Leitura e Produção de Textos) e os materiais didáticos (livros didáticos e, recentemente, os Cadernos do professor e do aluno, formulados e implementados com a intenção de uniformizar e reorganizar o ensino básico) também denotam uma preocupação constante com o ensino de leitura e escrita. Entretanto, pouco se diz a respeito da necessária abordagem dos referenciais sociais, culturais e os anseios do aluno durante as atividades práticas (supostos na teoria bakhtiniana de base). Essas orientações de cunho teórico-metodológico parecem, segundo diferentes fontes, ${ }^{2}$ não ser bem compreendidas e praticadas no cotidiano escolar, tanto por parte dos alunos quanto dos professores. A leitura escolar, literária ou não, idealmente exige que o aluno seja letrado, que consiga transitar pelos conteúdos e ter domínio da linguagem utilizada nos textos, que possa refletir sobre aquilo que está lendo, sendo capaz de abstrair ideias, concatenado-as e organizando-as de modo que o escrito faça sentido para ele enquanto sujeito leitor e enquanto indivíduo. Espera-se ainda que o educando adquira uma postura mais crítica perante o mundo e que consiga desempenhar plenamente a sua capacidade leitora (leituras de diferentes gêneros e tipos textuais e situações de comunicação diversas).É difícil, no entanto, pelas próprias características dos gêneros literários, estabelecer um parâmetro seguro de quais textos despertariam o interesse dos alunos em leituras literárias mediadas pela escola, sejam 
aquelas realizadas em sala de aula, com a presença do professor, lidas em voz alta ou individualmente, sejam as realizadas em casa pelo aluno sob a orientação prévia do professor, como leituras dirigidas. $\mathrm{O}$ alcance que o texto literário tem no imaginário do aluno é impossível de ser mensurado de fato uma vez que depende do repertório e dos referenciais desse sujeito. Contudo, é possível discutir aspectos ligados à valoração da recepção desses textos com o suporte das teorias ligadas à recepção do texto literário (JAUSS, 2002; FISH, 1980).

A pesquisa se apoiará, em princípio, nas teorias da recepção, para abordar as diferentes leituras possíveis nas práticas teatrais, considerando as maneiras de ler (CHARTIER, 2001) do jovem e suas contribuições particulares ao longo do processo enquanto parte fundamental do ato de leitura:

Uma história do ler afirmará [...] que as significações dos textos, quaisquer que sejam, são constituídas, diferencialmente, pelas leituras que se apoderam deles. Daí, uma dupla consequiência. Antes de mais nada, dar à leitura o estatuto de uma prática criadora, inventiva, produtora, e não anulá-la no texto lido, como se o sentido desejado por seu autor devesse inscrever-se com toda a imediatez e transparência, sem resistência nem desvio, no espírito de seus leitores. Em seguida, pensar que os atos de leitura que dão aos textos significações plurais e móveis situam-se no encontro de maneiras de ler, coletivas ou individuais, herdadas ou inovadoras, íntimas ou públicas e de protocolos de leitura depositados no objeto lido (CHARTIER, 2001, p.78).

Ainda sobre as relações do texto-leitor envolvidas na leitura, a pesquisa intenta verificar como se dá essa passagem dos "sistemas fechados de leitura" (ISER, 2002), de decifração dos textos para um "sistema mais aberto", aquele que considera que o leitor deverá preencher os vazios textuais, as lacunas, com suas interpretações e referenciais específicos, ou seja, o que Iser chama de seus modos de criação de mundo. ${ }^{3}$ Como seriam esses modos de criação de mundo nas leituras realizadas por jovens em outras situações de comunicação, que não escolares, e quais seriam os textos (e a maneira de lê-los) capazes de motivá-los?

Traçando um breve paralelo com a teoria dos gêneros, Dolz e Schneuwly, em artigo sobre os gêneros textuais escolares, apontam para a importância de se saber o quê, para quem, e como se escreve, quando se elabora uma produção textual na escola, considerando que há um desdobramento dos gêneros que são adotados nas situações de ensino. ${ }^{4}$ É possível depreender do artigo mencionado que, para que o aluno efetivamente se aproprie da escrita, seria interessante que ele tivesse acesso não apenas a indicações e sugestões que resultem, como produto final, em textos escolarizados, 
Revista "AspaS" - № 1 - 2011 - Anais do Primeiro Seminário de Pesquisas em Andamento ppgac do Programa de Pós-Graduação em Artes Cênicas da Universidade de São Paulo.

descontextualizados ou esvaziados de sentido, o que possivelmente implicaria em ausência de compreensão e falta de comprometimento por parte de quem escreve (no caso, o aluno), ou seja, em uma não autoria.

Nas leituras observadas durante os processos de pesquisa e criação do grupo de teatro Cia. Antropofágica, os textos pareciam adquirir muita importância para os leitores jovens. Geralmente, as leituras recomendadas estavam relacionadas ao tema da peça a se representar posteriormente ou a um assunto discutido coletivamente. Em um dos processos (do qual participei como integrante do grupo), tratava-se da montagem de um espetáculo cuja dramaturgia se reportava a textos brechtianos de cunho essencialmente social, com indicação de leituras relacionadas ao assunto, entre elas uma apostila que trazia trechos sobre os princípios norteadores do grupo (visando à formação de um "ator antropofágico", fundamentada em teóricos e escritores como Oswald de Andrade, Benedito Nunes, Mário de Andrade, Montaigne etc.). A recomendação bibliográfica, porém, não se restringia a autores e obras estritamente relacionados à peça, e os envolvidos, se não chegavam a ler todos os textos, pareciam esforçar-se em entender e participar daquilo que era discutido após a leitura na roda de debates.

Investigar, portanto, as leituras realizadas por jovens inseridos em processos criativos de grupos de teatro, cotejá-las brevemente com as leituras realizadas na escola, verificar que elementos estão envolvidos nas leituras feitas em coletivos teatrais e qual o seu lugar ou valor entre os seus integrantes é o intuito desse projeto de pesquisa. Partindo dessa investigação, talvez seja possível ainda dela depreender se haveria uma concepção de formação, explícita ou implícita, que se funda a partir das ações dos grupos fomentados junto àqueles a quem se reportam.

A pesquisa é de cunho qualitativo, feita a partir de um prévio levantamento dos grupos teatrais que se encaixam nos aspectos procurados (grupos que trabalham com jovens ou que apresentam em seus projetos ações de cunho formativo) via análise dos projetos dos grupos teatrais paulistanos contemplados pela Lei de Fomento. Esse recorte foi escolhido primeiramente em função da necessidade de se fazer uma distinção de grupos que apresentam uma proposta contínua de trabalho, em detrimento de outros que apenas trabalham com eles pontualmente e, em segundo lugar, pelo fato de serem aparentemente "legitimados" pelo poder público, na medida em que recebem verba municipal para sustentar o projeto que desenvolvem. 
A análise tanto dos projetos submetidos à análise da banca do fomento, quanto dos sites e do material disponível à consulta será comparada com o que se observa/observará na prática efetiva do desenvolvimento das atividades propostas.

A observação dos processos e da prática está sendo realizada com o intuito de se conhecer como se dão os processos de leitura, pesquisa e criação de cada grupo. Essas observações feitas sob a ótica do observador deverão, no entanto, ser problematizadas e confrontadas com os dados colhidos em entrevistas e questionários respondidos pelos envolvidos em cada grupo. A ideia é manter um contato mais dialógico, polifônico e menos prescritivo, com os processos criativos teatrais, nos quais a leitura se encontra imbricada, a fim de se obter um parecer mais aprofundado e verdadeiro do objeto de pesquisa, mesmo que para além dos rumos previstos.

\section{Referências}

BRASIL, Ministério da Educação/ Secretaria de Educação Básica. Conhecimentos de Literatura. In: Linguagens, códigos e suas tecnologias. Brasília: MEC/SEB, 2006.

CHARTIER, Roger (Org.). Práticas da leitura. São Paulo: Estação Liberdade, 2001.

COSTA, Iná Camargo; CARVALHO, Dorberto. A luta dos grupos teatrais de São Paulo por políticas públicas para a cultura: os cinco primeiros anos da lei de fomento ao teatro. São Paulo: Cooperativa Paulista de Teatro, 2008.

FISH, Stanley. Interpreting the Variorum. In: Is there a text in this class?: The authority of interpretive communities. Cambridge: Harvard University Press, 1980.

FAVARETTO, Celso. Arte contemporânea e educação. Revista Iberoamericana de Educación, Organização dos Estados Ibero-Americanos (OEI), n. 53, p. 225-235, 2010.

Entre o moderno e o contemporâneo. Revista Tempo e Memória, São Paulo, Universidade São Marcos, n. 4, p.49-66, jan.-jul. 2005.

ISER, Wolfang. O jogo do texto. In: LIMA, L.C. (Org.). A literatura e o leitor. Rio de Janeiro: Paz e Terra, 2002.

JAUSS, H. R. A estética da recepção. In: LIMA, L.C. (Org.). A literatura e o leitor. Rio de Janeiro: Paz e Terra, 2002a.

O prazer estético e as experiências fundamentais da poiesis, aisthesis e khatarsis. In: LIMA, L. C. (Org.). A literatura e o leitor. Rio de Janeiro: Paz e Terra, 2002b. 
JOUVE, Vincent. A leitura. São Paulo: Editora Unesp, 2002.

ROUXEL, A.; LANGLADE, G. Le sujet lecteur: lecture subjective et enseignement de la littérature. Rennes: PUR, 2004.

SCHNEUWLY, Bernard; DOLZ, Joaquim. Os gêneros escolares - das práticas de linguagem aos objetos de ensino. Revista Brasileira de Educação, n. 11, mai/jun/jul/ago. 1999.

\section{Notas:}

${ }^{1}$ Colocação do diretor do Teatro da Vertigem e professor da ECA-USP, Antônio Araújo.

2 Relatórios de estágio colhidos em Metodologia do Ensino de Língua Portuguesa, pesquisas em andamento na área de Linguagem e Educação da FEUSP e artigos, em especial o artigo "A percepção de gêneros textuais discursivos do professor de língua materna", de Alessandra Baldo.

3 "Desde o advento do mundo moderno há uma tendência clara em privilegiar-se o aspecto performativo da relação autor-leitor-texto, pelo qual o pré-dado não é mais visto como um objeto de representação, mas sim como o material a partir do qual algo novo é modelado. O novo produto, entretanto, não é predeterminado pelos traços, funções e estruturas do material referido e contido no texto. Quando [...] o sistema fechado é perfurado e substituído por um sistema aberto, o componente mimético da representação declina e o aspecto performativo assume o primeiro plano. O processo então não mais implica vir aquém das aparências para captar um mundo inteligível, no sentido platônico, mas se converte em um "modo de criação de mundo"” (ISER, 2002, p. 105-106).

4 “A particularidade da situação escolar reside no fato que torna a realidade bastante complexa: há um desdobramento que se opera, em que o gênero não é mais um instrumento de comunicação somente, mas, ao mesmo tempo, objeto de ensino/aprendizagem. $\mathrm{O}$ aluno encontra-se, necessariamente, num espaço do como se, em que o gênero funda uma prática de linguagem que é, necessariamente, em parte, fictícia, uma vez que ela é instaurada com fins de aprendizagem. [...] No desdobramento mencionado, é produzida uma inversão em que a comunicação desaparece quase totalmente em prol da objetivação e o gênero torna-se uma pura forma lingüística cujo objetivo é o seu domínio" (SCHNEUWLY; DOLZ, 1999, p. 8). 